\title{
Serum kisspeptin concentrations are negatively correlated with body mass index in adolescents with anorexia nervosa and amenorrhea
}

\author{
Flora Bacopoulou, ${ }^{1}$ George I. Lambrou, ${ }^{1}$ Maria-Evangelia Rodanaki, ${ }^{2}$ Evgenia Stergioti, ${ }^{1}$ \\ Vasiliki Efthymiou, ${ }^{1}$ Efthymios Deligeoroglou, ${ }^{1}$ Sophia L. Markantonis ${ }^{2}$
}

${ }^{1}$ Center for Adolescent Medicine and UNESCO Chair on Adolescent Health Care, First Department of Pediatrics, School of Medicine, National and Kapodistrian University of Athens, Aghia Sophia Children's Hospital, Athens, Greece; ${ }^{2}$ Faculty of Pharmacy, Department of Pharmaceutical Technology, Laboratory of Biopharmaceutics and Pharmacokinetics, National and Kapodistrian University of Athens, Athens, Greece

\begin{abstract}
OBJECTIVE: To measure, for the first time, serum kisspeptin concentrations in adolescent females with anorexia nervosa (AN) and associated amenorrhea, and investigate potential correlations of kisspeptin with anthropometric, bone and hormonal data. DESIGN: Setting: University Adolescent Medicine Center. Participants: Females aged 12-20 years with typical or atypical AN (based on DSM-5 diagnostic criteria) and controls. Interventions: Measurement of body mass index (BMI), whole body/lumbar spine bone mineral density and serum concentrations of kisspeptin, follicle stimulating hormone, luteinizing hormone (LH), prolactin (PRL), thyroid stimulating hormone (TSH), free thyroxine, triiodothyronine, estradiol $\left(\mathrm{E}_{2}\right)$, 17-hydroxyprogesterone. Main Outcome Measures: Kisspeptin serum concentrations and correlations between kisspeptin and $\mathrm{AN}$-related anthropometric, bone and hormonal changes. RESULTS: Participants included 37 females, 22 with AN (typical AN group=17, atypical AN group=5) and 15 in the control group. All typical AN patients had secondary amenorrhea. Wide inter-subject variation (101.9-709.1 ng/L) in kisspeptin levels was observed with no significant differences among study groups; there was a trend toward higher concentrations in the atypical AN group. Adolescents with typical AN had significantly lower BMI $(P<0.001)$, lumbar spine z-score $(P=0.016)$, serum $E_{2}(P<0.001)$, LH $(P=0.016)$, PRL $(P=0.034)$ and TSH $(P=0.045)$ than controls. They also had lower BMI $(P=0.009)$ and TSH $(P=0.027)$ than girls with atypical AN. An inverse correlation between BMI and serum kisspeptin was noted in the typical AN group $(r=-0.60, P=0.012)$. CONCLUSIONS: Serum kisspeptin concentrations overlapped between
\end{abstract}




\section{patients and controls; in typical anorexic adolescents kisspeptin concentrations were negatively correlated with BMI. Future studies are needed to explore kisspeptin physiology in AN.}

Key words: Adolescents, Anorexia nervosa, Eating disorders, Hypothalamic amenorrhea, Kisspeptin, Young women

\section{INTRODUCTION}

Anorexia nervosa (AN) is a psychiatric disorder that affects mostly young women with a 12-month prevalence of approximately $0.4 \% .{ }^{1}$ Typical diagnostic criteria include severe undernutrition, body image distortion and intense fear of becoming fat. When the presentation does not meet all diagnostic criteria, the disorder is characterized as atypical AN under the category of 'Other Specified Feeding or Eating Disorder', according to the recent DSM-5 classification. ${ }^{1}$ Conditions of undernutrition as in typical or atypical AN are frequently linked to reproductive disorders, i.e. amenorrhea and subfertility. ${ }^{2,3}$ Although a plethora of neuroendocrine regulators that participate in the metabolic control of reproductive function have been identified, the underlying mechanism of the regression of the hypothalamic-pituitary-gonadal (HPG) axis in patients with $\mathrm{AN}$ is still unclear.

Over the past decade, the discovery of the hypothalamic neuropeptide kisspeptin and its receptor KISS1R has increasingly focused research on this peptide as a putative regulator of the HPG axis and reproductive function. ${ }^{3}$ Kisspeptin directly activates the gonadotropin-releasing hormone $(\mathrm{GnRH})$ neurons which express KISS1R to release GnRH into the portal circulation and, thus, stimulate the secretion of luteinizing hormone (LH) and follicle stimulating hormone (FSH) from the anterior pituitary. ${ }^{4}$ In women with functional hypothalamic amenorrhea, the reactivation of $\mathrm{GnRH} / \mathrm{LH}$ pulsatility by kisspeptin administration suggests that exogenous kisspeptin enters the central nervous system somehow crossing the blood-brain barrier. ${ }^{5}$ Studies in energy-depleted animals with hypogonadotropic hypogonadism have reported a reduction in hypothalamic kisspeptin mRNA as well as in circulating LH levels. ${ }^{2}$ To what extent hypothalamic mRNA changes due to undernutrition translate into alterations of kisspeptin release in the circulation remains as yet unknown.
To the best of our knowledge, no data are available on circulating kisspeptin in women with hypothalamic amenorrhea due to anorexia nervosa. The aim of this study was to measure serum kisspeptin concentrations in anorexic girls with associated amenorrhea and in healthy adolescent females and to investigate potential correlations of kisspeptin with anthropometric, bone and hormonal parameters.

\section{MATERIALS AND METHODS}

\section{Study Participants}

Participants included adolescent females, aged 12 to 20 years, with typical or atypical anorexia nervosa (restricting type) as well as healthy controls who presented to the outpatient clinic of our tertiary Center for Adolescent Medicine over a period of four years, from January 2012 until January 2016. All participants were consecutively recruited in order to avoid any bias based on patient selection. Controls were age-matched girls who presented for a routine annual health examination. Patients were assessed on first presentation by a team of adolescent medicine physicians (adolescent medicine pediatrician, psychiatrist, gynecologist and dietician) and underwent a detailed physical, cardiac, biochemical, hormonal and mental assessment. Measurements of height and weight were performed in all participants and body mass index (BMI) was calculated as weight in kilograms divided by the square of height in meters. The diagnosis of each type of eating disorder was made by the adolescent medicine team on the basis of the DSM-5 diagnostic criteria. ${ }^{1}$ Each adolescent female with AN had to be clinically stable to attend on an outpatient basis. Exclusion criteria included a prior history of an eating disorder, pregnancy and the presence of any comorbidity or pharmacological treatment. The study was approved by the institutional ethics committee (protocol number 28126) and was conducted according to the principles of the Helsinki 
Declaration. The adolescent girls and their parents were informed about the nature of the study and written informed consent was obtained prior to participation.

\section{Bone Mineral Density Measurements}

Areal bone mineral density (BMD) of the whole body (WB) and lumbar spine (LS) vertebrae L1 to L4 were measured by dual-energy X-ray absorptiometry (DXA) using a Lunar Prodigy Pro DXA scanner (GE Healthcare Technologies, Waukesha, WI, USA). Respective z-scores, adjusted for age and sex, were provided by the densitometer for each study participant.

\section{Hormonal Measurements}

Venous blood samples were drawn from the normally menstruating adolescents between the $3 \mathrm{rd}$ and 5 th days of their menstrual cycle. Samples were obtained on random days from amenorrheic patients. Immediately after blood collection, the samples were left for 20 minutes at room temperature and then centrifuged for 20 minutes at $3000 \mathrm{rpm}$. Supernatant serum was collected and the levels of FSH, LH, prolactin (PRL), thyroid-stimulating hormone (TSH), free thyroxine (FT4), triiodothyronine (T3), estradiol $\left(\mathrm{E}_{2}\right)$ and 17-hydroxyprogesterone (17OHP) were determined for each adolescent. The remaining serum was immediately stored at $-80^{\circ} \mathrm{C}$ for analysis of kisspeptin concentrations for all study participants.

Serum kisspeptin concentrations were measured on a UV-visible photometer (Awareness Technologies Stat Fax 2100 Microplate Reader) using an enzymelinked immune sorbent assay (KISS1 ELISA Kit, EMELCA Bioscience, The Netherlands) based on the biotin double antibody sandwich technology to assay the human Kisspeptin 1 (metastin). The assay sensitivity was $12.14 \mathrm{ng} / \mathrm{L}$ and intra- and inter-assay coefficients of variation (CVs) were $<10 \%$ and $<12 \%$, respectively, with a range of 20-1500 ng/L. In accordance with the manufacturer's instructions, no significant cross-reactivity or interference between Kisspeptin 1 and analogues were observed.

Serum levels of FSH, LH, PRL, TSH, FT4, T3, $\mathrm{E}_{2}$ were measured on an immulite 2000 analyzer (Siemens Healthcare Diagnostics Products Ltd., UK) using two-site chemiluminescent immunometric assays and serum levels of $17 \mathrm{OHP}$ were determined by RIA (DIAsource).

\section{Statistical Analysis}

Statistical analyses were performed with the use of SPSS version 21 software package and the MATLAB computational environment (The Mathworks, Inc. Natick, MA, USA). To test the assumption of normality for each variable the Shapiro-Wilk test was used. The non-parametric Mann-Whitney and Kruskal-Wallis tests were performed to examine group differences in serum kisspeptin and other hormonal concentrations and non-parametric Spearman's rho to examine correlations between the variables. Data were expressed as median, range and statistical significance was set at $P$-values $<0.05$. Regression analysis was performed using polynomial function.

\section{RESULTS}

A total of 37 adolescent females participated in the study, 22 patients with anorexia nervosa and 15 agematched controls (control group). The patient group consisted of 17 patients with AN who fulfilled all diagnostic criteria for the disease (typical AN group) and 5 patients with atypical AN (atypical AN group). All patients from the typical AN group and 3 girls from the atypical AN group had secondary amenorrhea of more than 3 months duration. All participants had normal electrocardiogram and cardiac ultrasounds and normal serum glucose, electrolytes, renal and liver function. Participant data are summarized in Table 1.

\section{Patient Groups Comparisons}

Statistically significant differences were found among the three study groups, typical AN, atypical $\mathrm{AN}$ and control groups, with respect to BMI (Figure 1A), TSH (Figure 1B), LH (Figure 1C), $\mathrm{E}_{2}$ (Figure 1D), PRL (Figure 1E) and LS z-score (Figure 1F). Patients with typical AN had significantly lower BMI and TSH levels than those with atypical $\mathrm{AN}(P=0.009$, $P=0.027$, respectively $)$ and controls $(P<0.001, P=0.045$, respectively). Patients with typical $\mathrm{AN}$ also had significantly lower levels of $\mathrm{E}_{2}(P<0.001), \mathrm{LH}(P=0.016)$ and PRL $(P=0.034)$ as well as LS z-scores $(P=0.016)$ than controls.

\section{Serum Kisspeptin Concentrations}

There was a large variation in serum kisspeptin concentrations that ranged between 101.9 and 709.1 $\mathrm{ng} / \mathrm{L}$ in the adolescents studied, as shown in Table 
Table 1. Characteristics of patient (typical and atypical $\mathrm{AN}^{\mathrm{a}}$ ) and control groups

\begin{tabular}{|c|c|c|c|c|c|c|c|c|}
\hline & $\begin{array}{c}\text { Total participants } \\
n=37\end{array}$ & $\begin{array}{c}\text { Typical AN } \\
n=17\end{array}$ & $\begin{array}{c}\text { Atypical AN } \\
n=5\end{array}$ & $\begin{array}{c}\text { Controls } \\
n=15\end{array}$ & $P^{*}$ & $\boldsymbol{P}^{\dagger}$ & $P$ & $P$ \\
\hline $\begin{array}{l}\text { Age, years } \\
\text { (median, range) }\end{array}$ & $\begin{array}{c}14.7 \\
(12.8-19.5)\end{array}$ & $\begin{array}{c}15.1 \\
(13.6-17.3)\end{array}$ & $\begin{array}{c}14.5 \\
(13.3-17.1)\end{array}$ & $\begin{array}{c}14.3 \\
(12.8-19.5)\end{array}$ & 0.217 & 0.086 & 0.793 & 0.388 \\
\hline $\begin{array}{l}\mathrm{BMI}^{\mathrm{b}}, \mathrm{kg} / \mathrm{m}^{2} \\
\text { (median, range) }\end{array}$ & $\begin{array}{c}17.2 \\
(13.6-23.3)\end{array}$ & $\begin{array}{c}15.9 \\
(13.6-17.2)\end{array}$ & $\begin{array}{c}18.3 \\
(16.0-22.9)\end{array}$ & $\begin{array}{c}19.8 \\
(17.2-23.4)\end{array}$ & $<0.001$ & $<0.001$ & 0.266 & 0.009 \\
\hline $\begin{array}{l}\text { Amenorrhea, months } \\
\text { (median, range) }\end{array}$ & & $\begin{array}{c}8.5 \\
(4.1-30)\end{array}$ & $\begin{array}{c}6.1 \\
(4-10.2)\end{array}$ & & & & & 0.614 \\
\hline $\begin{array}{l}\mathrm{LS}^{\mathrm{c}} \mathrm{z} \text {-score } \\
\text { (median, range) }\end{array}$ & $\begin{array}{c}-0.8 \\
(-2.5-1.0)\end{array}$ & $\begin{array}{c}-1.4 \\
(-2.5-0.3)\end{array}$ & $\begin{array}{c}-0.8 \\
(-1.7-0.2)\end{array}$ & $\begin{array}{c}0.1 \\
(-1.0-1.0)\end{array}$ & 0.050 & 0.016 & 0.317 & 0.551 \\
\hline $\begin{array}{l}\mathrm{WB}^{\mathrm{d}} \mathrm{Z} \text {-score } \\
\text { (median, range) }\end{array}$ & $\begin{array}{c}0.2 \\
(-1.7-1.2)\end{array}$ & $\begin{array}{c}-1.0 \\
(-1.7-0.5)\end{array}$ & $\begin{array}{c}0.6 \\
(-0.3-0.6)\end{array}$ & $\begin{array}{c}0.5 \\
(-0.2-1.2)\end{array}$ & 0.256 & 0.212 & 0.480 & 0.180 \\
\hline $\begin{array}{l}\text { Kisspeptin, ng/L } \\
\text { (median, range) }\end{array}$ & $\begin{array}{c}229.6 \\
(101.9-709.1)\end{array}$ & $\begin{array}{c}208.2 \\
(110.0-586.0)\end{array}$ & $\begin{array}{c}436.9 \\
(167.3-641.4)\end{array}$ & $\begin{array}{c}232.8 \\
(101.9-709.1)\end{array}$ & 0.169 & 0.546 & 0.176 & 0.055 \\
\hline $\begin{array}{l}\mathrm{LH}^{\mathrm{e}}, \mathrm{mIU} / \mathrm{mL} \\
\text { (median, range) }\end{array}$ & $\begin{array}{c}2.85 \\
(0.01-24.47)\end{array}$ & $\begin{array}{c}0.65 \\
(0.01-9.2)\end{array}$ & $\begin{array}{c}5.20 \\
(3.6-6.0)\end{array}$ & $\begin{array}{c}4.86 \\
(0.07-24.40)\end{array}$ & 0.028 & 0.016 & 0.938 & 0.069 \\
\hline $\begin{array}{l}\mathrm{FSH}^{\mathrm{f}}, \mathrm{mIU} / \mathrm{mL} \\
\text { (median, range) }\end{array}$ & $\begin{array}{c}4.04 \\
(0.05-11.81)\end{array}$ & $\begin{array}{c}3.78 \\
(0.39-11.81)\end{array}$ & $\begin{array}{c}4.40 \\
(3.6-5.0)\end{array}$ & $\begin{array}{c}4.56 \\
(0.05-6.50)\end{array}$ & 0.664 & 0.401 & 0.696 & 0.638 \\
\hline $\begin{array}{l}\mathrm{PRL}^{\mathrm{g}}, \mathrm{ng} / \mathrm{mL} \\
\text { (median, range) }\end{array}$ & $\begin{array}{c}9.4 \\
(3.3-31.4)\end{array}$ & $\begin{array}{c}6.7 \\
(3.3-17.3)\end{array}$ & $\begin{array}{c}12.5 \\
(6.7-18.3)\end{array}$ & $\begin{array}{c}12.6 \\
(6.2-31.4)\end{array}$ & 0.092 & 0.034 & 0.830 & 0.283 \\
\hline $\begin{array}{l}\mathrm{TSH}^{\mathrm{h}}, \mathrm{mU} / \mathrm{mL} \\
\text { (median, range) }\end{array}$ & $\begin{array}{c}1.96 \\
(0.67-8.15)\end{array}$ & $\begin{array}{c}1.43 \\
(0.67-2.49)\end{array}$ & $\begin{array}{c}2.48 \\
(1.46-4.70)\end{array}$ & $\begin{array}{c}2.21 \\
(0.94-8.15)\end{array}$ & 0.042 & 0.045 & 0.598 & 0.027 \\
\hline $\begin{array}{l}\mathrm{FT} 4{ }^{\mathrm{i}}, \mathrm{ng} / \mathrm{dL} \\
\text { (median, range) }\end{array}$ & $\begin{array}{c}1.1 \\
(0.85-1.31)\end{array}$ & $\begin{array}{c}1.06 \\
(0.85-1.27)\end{array}$ & $\begin{array}{c}1.10 \\
(0.91-1.22)\end{array}$ & $\begin{array}{c}1.22 \\
(0.97-1.31)\end{array}$ & 0.248 & 0.150 & 0.197 & 0.606 \\
\hline $\begin{array}{l}\mathrm{T}^{\mathrm{j}}, \mathrm{ng} / \mathrm{mL} \\
\text { (median, range) }\end{array}$ & $\begin{array}{c}1.22 \\
(0.43-1.55)\end{array}$ & $\begin{array}{c}1.18 \\
(0.43-1.37)\end{array}$ & $\begin{array}{c}1.43 \\
(0.47-1.51)\end{array}$ & $\begin{array}{c}1.22 \\
(1.06-1.55)\end{array}$ & 0.505 & 0.357 & 0.683 & 0.275 \\
\hline $\begin{array}{l}\mathrm{E}_{2}{ }^{\mathrm{k}}, \mathrm{pg} / \mathrm{mL} \\
\text { (median, range) }\end{array}$ & $\begin{array}{c}23 \\
(5-270)\end{array}$ & $\begin{array}{c}12.7 \\
(5.0-28.0)\end{array}$ & $\begin{array}{c}44.3 \\
(12.0-74.0)\end{array}$ & $\begin{array}{c}42.1 \\
(23.0-270)\end{array}$ & $<0.001$ & $<0.001$ & 0.926 & 0.086 \\
\hline $\begin{array}{l}17 \mathrm{OHP}^{1}, \mathrm{ng} / \mathrm{mL} \\
\text { (median, range) }\end{array}$ & $\begin{array}{c}1.20 \\
(0.62-1.85)\end{array}$ & $\begin{array}{c}1.16 \\
(0.62-1.50)\end{array}$ & $\begin{array}{c}0.94 \\
(0.70-1.18)\end{array}$ & $\begin{array}{c}1.34 \\
(0.90-1.85)\end{array}$ & 0.16 & 0.18 & 0.37 & 0.12 \\
\hline
\end{tabular}

$P^{*}$ represents $P$-value among the three groups; $P^{\dagger}$ represents $P$-value between typical AN and controls; $P^{\ddagger}$ represents $P$-value between atypical AN and controls; $P^{\sharp}$ represents $P$-value between typical and atypical AN.

${ }^{\mathrm{a}} \mathrm{AN}$ : anorexia nervosa; ${ }^{\mathrm{B} B M I}$ : body mass index; ${ }^{\mathrm{C} L S}$ : lumbar spine; ${ }^{\mathrm{d} W B}$ : whole body; ${ }^{\mathrm{e}} \mathrm{HH}$ : luteinizing hormone; ${ }^{\mathrm{f} F S H}$ : follicle stimulating hormone; ${ }^{g} \mathrm{PRL}$ : prolactin; ${ }^{\mathrm{h}} \mathrm{TSH}$ : thyroid stimulating hormone; ${ }^{\mathrm{i}} \mathrm{FT} 4$ : free thyroxine; ${ }^{\mathrm{i} T 3}$ : triiodothyronine; ${ }^{\mathrm{E}} \mathrm{E}_{2}$ : estradiol; '17OHP: 17-hydroxyprogesterone.

1. No significant differences were found among the study groups with respect to kisspeptin levels. The pattern of change of serum kisspeptin levels among the three study groups is presented diagrammatically in Figure 2. Kisspeptin levels were lower in the AN and control groups and higher in the atypical AN group, but these differences did not reach statistical significance.

In the atypical AN subgroup, the girls with amenorrhea (three patients) had lower levels of serum kiss- peptin (mean \pm SD: $392.01 \pm 173.45 \mathrm{ng} / \mathrm{L}$ ) than those (two patients) in whom menstruation was preserved (mean \pm SD: $539.14 \pm 102.27 \mathrm{ng} / \mathrm{L}$ ).

\section{Correlation - Regression Analyses}

For all study participants, statistically significant positive correlations were found between BMI and $\mathrm{E}_{2}(r=0.62, P=0.001)$. Furthermore, significant weak positive correlations were found between $\mathrm{BMI}$ and $\mathrm{LH}$ $(r=0.49, P=0.010)$, PRL $(r=0.53, P=0.011)$ and TSH $(r=0.40, P=0.040)$. Significant positive correlations 

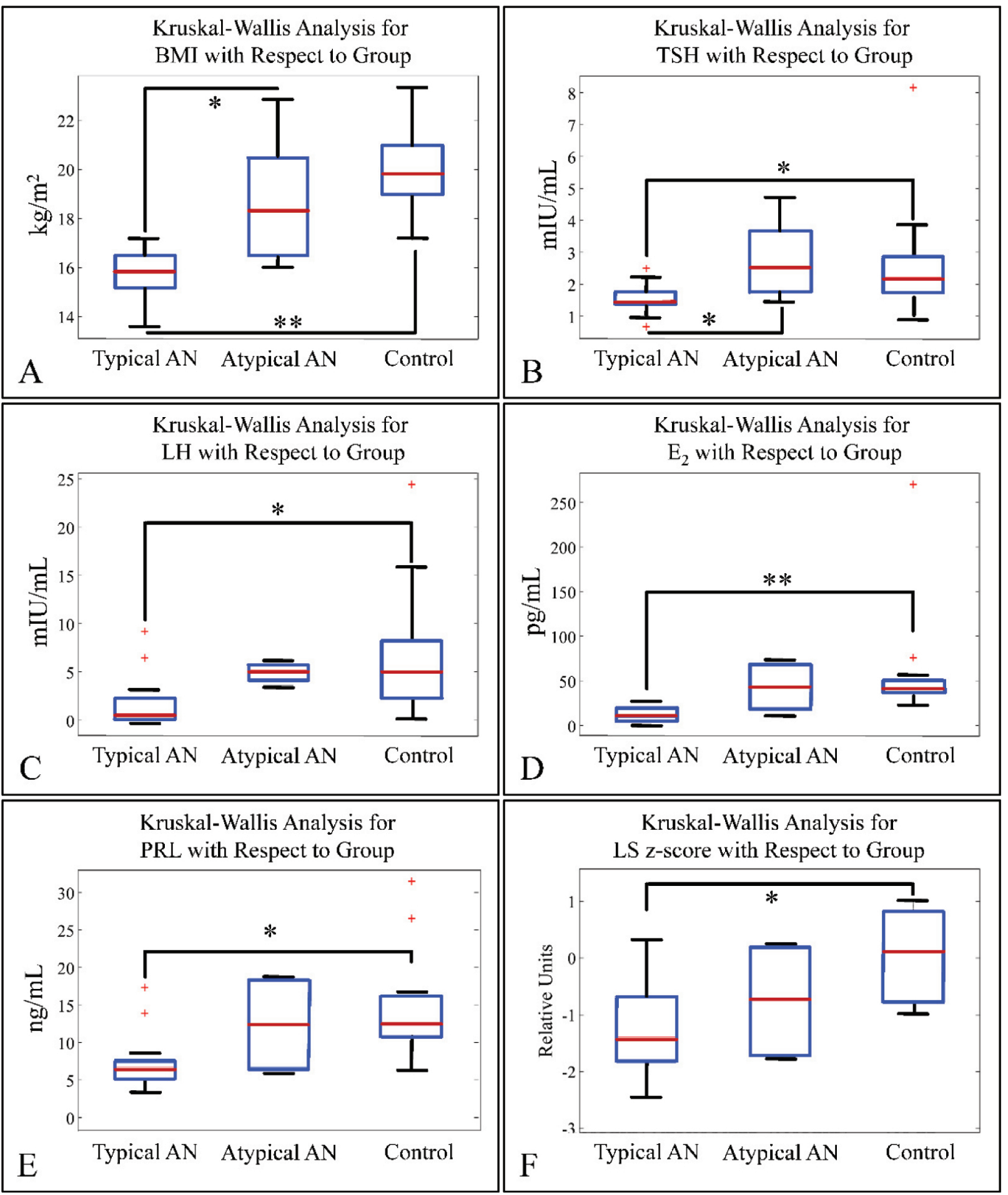

Figure 1. Diagrammatic presentation of significant differences between study groups (typical AN, atypical AN and control groups) with respect to (A) BMI, between typical and atypical AN $\left({ }^{*} P=0.009\right)$ and between typical AN and control $(* * P<0.001)$, (B) TSH, between typical AN and control $(* P=0.045)$ and between typical and atypical AN $(* P=0.027),(\mathbf{C}) \mathrm{LH}$, between typical AN and control $(* P=0.016),(\mathbf{D}) \mathrm{E}_{2}$, between typical AN and control $(* * P<0.001),(\mathbf{E})$ PRL, between typical AN and control $(* P=0.034)$ and $(\mathbf{F})$ LS $\mathrm{Z}$-score between typical AN and control $(* P=0.016)$.

AN: anorexia nervosa; BMI: body mass index; TSH: thyroid stimulating hormone; LH: luteinizing hormone; E2: estradiol; PRL: prolactin; LS: lumbar spine. 


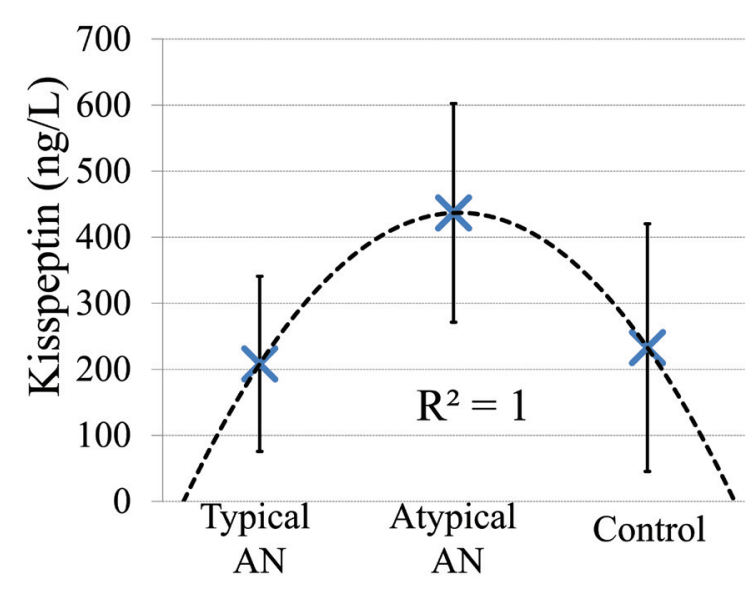

Figure 2. Diagrammatic presentation of serum kisspeptin concentrations among study groups (typical AN, atypical AN and control groups) using polynomial regression analysis.

AN: anorexia nervosa.

were also found between the reproductive hormones LH and FSH $(r=0.69, P<0.001), \mathrm{LH}$ and $\mathrm{E}_{2}(r=0.61$, $P=0.001)$. There were no statistically significant correlations between kisspeptin concentrations and the hormones studied.

Interestingly, a statistically significant negative correlation was found between kisspeptin concentrations and BMI only in the typical AN group $(r=-0.60$, $P=0.012$ ). Regression analysis demonstrated an inverse association between BMI and kisspeptin; serum kisspeptin concentrations were higher with decreasing BMI in the typical anorexic adolescents (Figure 3).

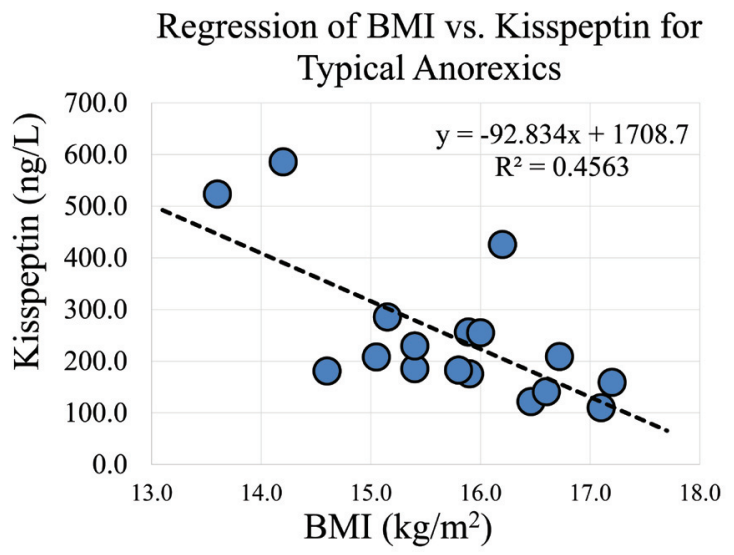

Figure 3. Regression of BMI vs. serum kisspeptin concentrations in adolescents with typical anorexia nervosa. BMI: body mass index.

\section{DISCUSSION}

The role of peripheral kisspeptin in amenorrhea induced by food restriction in anorexic females remains unexplored. As far as we are aware, this is the first study to compare kisspeptin blood levels among adolescent girls with typical or atypical anorexia nervosa and healthy controls.

Although it has not yet been clarified whether or not human kisspeptin secretion is pulsatile, the wide inter-subject variation in serum kisspeptin concentrations suggests that there could be an episodic release of kisspeptin. ${ }^{6}$ In addition, the pharmacokinetics of physiologic kisspeptin in humans and how this is modified according to disease states remains to be elucidated. The large variation in kisspeptin serum levels could be due to its short half-life ${ }^{7}$ or its circulation in peripheral body compartments, as the kisspeptin gene has been reported to be expressed in several peripheral organs, i.e. the pancreas, liver, small intestine, ovaries, adipose tissue and adrenal glands. ${ }^{8,9}$

Kisspeptin has been associated with the GnRH induced secretion of $\mathrm{LH}^{10}$ and, indeed, our patients with typical AN manifested significantly lower LH serum levels compared to controls, hence kisspeptin serum concentrations were expected to be significantly decreased in the former. Although serum levels of kisspeptin in the amenorrheic adolescents with typical AN were lower than those in the healthy normally menstruating adolescents, these differences were not statistically significant, as theoretically assumed. Most research on the central kiss1 system provides evidence of changes in the levels of hypothalamic mRNA following metabolic stress; however, it is not clear to what extent these mRNA changes translate into alterations of hypothalamic kisspeptin release or content. The absence of a correlation between central and peripheral kisspeptin, if central kisspeptin exerts its effects only within a limited area and cannot emerge in the peripheral circulation, and the existence of a negative feedback system between the female hypothalamus and peripheral organs could provide other possible explanations to our findings.

A more detailed illustration of kisspeptin concentrations in all study participants revealed a threshold pattern, with the levels being lower in patients with 
typical AN and controls and higher in patients with atypical AN. This pattern of change corresponds to the clinical spectrum of AN; atypical AN represents the clinical threshold in terms of body weight as well as mental and reproductive function prior to deterioration to typical AN. Interestingly, a similar pattern of change was observed in adult women in the study of Katagiri et al, ${ }^{11}$ who demonstrated a sharpened profile of plasma kisspeptin levels in perimenopausal (over age 38) women compared to younger and post-menopausal volunteers. The authors proposed the explanation that the strong stimulation from the hypothalamus in women approaching menopause released a large amount of circulating kisspeptin in order to support ongoing menstruation. Our findings support the aforementioned hypothesis in the disease state of anorexia nervosa. The relative elevation of kisspeptin levels in the participants with atypical anorexia whose ovarian function progressively weakened might have been triggered by hypothalamic secretion of kisspeptin in an effort to maintain menstruation. The exaggerated hypothalamic release might have resulted in a depletion of the kisspeptin reserve and thus in no further elevation in kisspeptin concentrations, as typical $\mathrm{AN}$ along with amenorrhea became established.

As expected, the amenorrheic adolescents of the typical AN group compared to the control group had significantly suppressed $\mathrm{LH}$ and $\mathrm{E}_{2}$ levels, indicative of the functional deficiency of gonadotropins that prevents gonadal steroid production in patients with AN. Estrogen deficiency, a major risk factor for developing low bone mass, explains our patients' deficits in bone density at the lumbar spine, typically seen in anorexia nervosa. ${ }^{12}$

Although prolactin levels are usually not altered in AN, ${ }^{13}$ our patients with typical AN had significantly lower PRL levels than controls. This finding, taken together with their low TSH levels, might be interpreted in the context of a general pituitary hypofunction in these subjects. This is further supported by the potential mechanism of hypothalamic suppression during prolonged fasting and illness caused by diminution in the set point of the hypothalamic-pituitary axis for feedback inhibition, reported by Warner et al. ${ }^{14}$

Patients with typical AN had significantly lower
BMIs than those with atypical AN, and even lower than controls. This was an expected finding in accordance with the definition ${ }^{1}$ of atypical AN, as all the criteria for anorexia nervosa were met, except that the individuals' weights were maintained within normal range. In patients with hypothalamic amenorrhea due to AN, the low BMI is usually associated with low serum estradiol and low serum gonadotropin levels. ${ }^{15}$ The failure of the pituitary to stimulate gonadal estradiol production reverses when undernutrition in anorexia nervosa improves. Consistent with the above, in this study participants' BMI was positively correlated with $\mathrm{E}_{2}$ and LH.

Both estrogen receptor alpha and progesterone receptor are expressed in kisspeptin cells, this suggesting that they play a role in mediating both negative and positive feedback effects of the sex steroids, estrogen and progesterone. ${ }^{16}$ However, we did not find any significant correlations between serum kisspeptin levels and either LH, FSH or estradiol levels. Also, we found no correlation between serum kisspeptin and BMI among the entire study participants. Similar observations have been reported in previous studies in women of different reproductive states as well as in healthy controls. A recent study of female students, 18-25 years old, did not find any association between serum kisspeptin levels and BMI or serum estradiol. ${ }^{17}$ Katagiri et al ${ }^{11}$ found no significant correlation between plasma kisspeptin levels and serum LH, FSH or estradiol levels in healthy females. In a recent work, Kanasaki et $a 1^{7}$ found no correlation of serum kisspeptin levels with levels of LH and FSH in normally menstruating women, pregnant women, postmenopausal women, patients with premature ovarian failure or idiopathic hypogonadotropic hypogonadism. Similarly, Panidis et $\mathrm{a}^{18}$ reported no significant correlation between plasma kisspeptin and LH levels in women with polycystic ovary syndrome (PCOS) and controls.

An interesting finding of this study is that when each group of participants was analyzed separately, an inverse association for kisspeptin serum levels with BMI was found only in the typical AN group. Consistent with our findings, Panidis et a $1{ }^{18}$ observed a negative correlation between BMI and plasma kisspeptin levels in women with PCOS. These findings contrast with the significant positive correlation be- 
tween BMI and visceral adipose tissue KISS1 mRNA levels in adult women as observed by Cockwell et al. ${ }^{19}$ Experimental studies have further confirmed that kisspeptin is expressed in adipose tissue and that kisspeptin receptors in adipose tissue are exposed, under some circumstances, to circulating kisspeptin. In addition, adipose tissue KISS 1 mRNA has been shown to be regulated by food intake and sex steroids; in the study of Brown et $\mathrm{al}^{20}$ it was reduced in obese and high fat diet rats and was increased by fasting and food restriction, perhaps as a response to falling blood levels of kisspeptins. The latter could provide a possible explanation for the significantly higher serum kisspeptin concentrations with decreasing BMI in our patients with typical AN. Future studies need to determine whether circulating kisspeptin levels are reduced by food restriction, as occurs in the hypothalamus, and whether adipose tissue KISS1 expression is increased by fasting, perhaps as a compensatory response, in patients with anorexia nervosa.

This study has some limitations. The number of participants was not equal between the study groups; the atypical AN group was very small and included two patients in whom menstruation was preserved. Nevertheless, the atypical AN group yielded unexpected results that merit further study. The wide inter-subject variation and overlap of serum kisspeptin concentrations suggests that further data in larger studies are needed in order to determine the exact role of circulating kisspeptin in the regulation of reproductive function in adolescents with restrictive eating disorders. The possible variation of serum kisspeptin across the menstrual cycle was another limitation that the study could not overcome, as almost all patients were amenorrheic.

In summary, serum kisspeptin concentrations overlapped between patients and controls and were negatively correlated with BMI in the adolescents with typical anorexia nervosa. Future studies are needed to provide definitive information about the human physiology of kisspeptin across the spectrum of anorexia nervosa.

\section{ACKNOWLEDGEMENTS}

We would like to thank Mr. Panagiotis Efentakis, MSc, for his help with the immunoassay measurement of kisspeptin.
The authors are responsible for the choice and presentation of views contained in this article and for opinions expressed therein, which are not necessarily those of the United Nations Educational, Scientific and Cultural Organization (UNESCO) and do not commit the organization.

\section{FINANCIAL SUPPORT STATEMENT}

There was no source of financial support for the study.

\section{CONFLICT OF INTEREST STATEMENT}

The authors have no conflict of interest to disclose.

\section{REFERENCES}

1. American Psychiatric Association 2015 Feeding and Eating Disorders. In: Diagnostic and Statistical Manual of Mental Disorders DSM-5, American Psychiatric Association Publishing, Arlington, VA; pp, 338-353.

2. Castellano JM, Navarro VM, Fernández-Fernández R, et al, 2005 Changes in hypothalamic KiSS-1 system and restoration of pubertal activation of the reproductive axis by kisspeptin in undernutrition. Endocrinology 146: 3917-3925.

3. Castellano JM, Bentsen AH, Mikkelsen JD, Tena-Sempere M, 2010 Kisspeptins: bridging energy homeostasis and reproduction. Brain Res 1364: 129-138.

4. Skorupskaite K, George JT, Anderson RA, 2014 The kisspeptin-GnRH pathway in human reproductive health and disease. Hum Reprod Update 20: 485-500.

5. Jayasena CN, Abbara A, Veldhuis JD, et al, 2014 Increasing LH pulsatility in women with hypothalamic amenorrhoea using intravenous infusion of Kisspeptin-54. J Clin Endocrinol Metab 99: E953-961.

6. George JT, Seminara SB, 2012 Kisspeptin and the hypothalamic control of reproduction: lessons from the human. Endocrinology 153: 5130-5136.

7. Kanasaki H, Purwana IN, Oride A, Mijiddorj T, Sukhbaatar U, Miyazaki K, 2013 Circulating kisspeptin and pituitary adenylate cyclase-activating polypeptide (PACAP) do not correlate with gonadotropin serum levels. Gynecol Endocrinol 29: 583-587.

8. Ohtaki T, Shintani Y, Honda S, et al, 2001 Metastasis suppressor gene KiSS-1 encodes peptide ligand of a G-protein-coupled receptor. Nature 411: 613-617.

9. Kauffman AS, 2010 Gonadal and nongonadal regulation of sex differences in hypothalamic Kiss1 neurones. J Neuroendocrinol 22: 682-691.

10. Navarro VM, Castellano JM, Fernández-Fernández R, et al, 2005 Characterization of the potent luteinizing 
hormone-releasing activity of KiSS-1 peptide, the natural ligand of GPR54. Endocrinology 146: 156163.

11. Katagiri F, Kotani M, Hirai T, Kagawa J, 2015 The relationship between circulating kisspeptin and sexual hormones levels in healthy females. Biochem Biophys Res Commun 458: 663-666.

12. Misra M, Aggarwal A, Miller KK, et al, 2004 Effects of anorexia nervosa on clinical, hematologic, biochemical, and bone density parameters in community-dwelling adolescent girls. Pediatrics 114: 1574-1583.

13. Misra M, Klibanski A, 2011 The neuroendocrine basis of anorexia nervosa and its impact on bone metabolism. Neuroendocrinology 93: 65-73.

14. Warner MH, Beckett GJ, 2010 Mechanisms behind the non-thyroidal illness syndrome: an update. J Endocrinol 205: 1-13.

15. Wierman ME, Rothman MS 2009 Amenorrhea. In: McDermott MT (ed) Endocrine Secrets, Mosby, Elsevier Inc, Philadelphia; pp, 401-402.
16. Foradori CD, Coolen LM, Fitzgerald ME, Skinner DC, Goodman RL, Lehman MN, 2002 Colocalization of progesterone receptors in parvicellular dynorphin neurons of the ovine preoptic area and hypothalamus. Endocrinology 143: 4366-4374.

17. Latif R, Rafique N, 2015 Serum kisspeptin levels across different phases of the menstrual cycle and their correlation with serum oestradiol. Neth J Med 73: $175-178$.

18. Panidis D, Rousso D, Koliakos G, et al, 2006 Plasma metastin levels are negatively correlated with insulin resistance and free androgens in women with polycystic ovary syndrome. Fertil Steril 85: 1778-1783.

19. Cockwell H, Wilkinson DA, Bouzayen R, Imran SA, Brown R, Wilkinson M, 2013 KISS1 expression in human female adipose tissue. Arch Gynecol Obstet 287: 143-147.

20. Brown RE, Imran SA, Ur E, Wilkinson M, 2008 KiSS-1 mRNA in adipose tissue is regulated by sex hormones and food intake. Mol Cell Endocr 281: 64-72. 